\title{
Early Effect of Single-dose Sitagliptin Administration on Gastric Emptying: Crossover Study Using the ${ }^{13} \mathrm{C}$ Breath Test
}

\author{
Takashi Nonaka, ${ }^{1}$ Yusuke Sekino, ${ }^{1}$ Hiroshi lida, ${ }^{1}$ Eiji Yamada, ${ }^{1}$ Hidenori Ohkubo, ${ }^{1}$ Eiji Sakai, ${ }^{1}$ Takuma Higurashi, ${ }^{1}$ \\ Kunihiro Hosono, ${ }^{1}$ Hiroki Endo, ${ }^{1}$ Tomoko Koide, ${ }^{1}$ Hirokazu Takahashi, ${ }^{1}$ Koji Fujita, ${ }_{1}$ Masato Yoneda, ${ }^{1}$ Ayumu Goto, \\ Akihiko Kusakabe, ${ }^{1}$ Noritoshi Kobayashi, ${ }^{1}$ Eiji Gotoh, ${ }^{2}$ Shin Maeda, ${ }^{1}$ Atsushi Nakajima, ${ }^{1}$ Chihiro Nosaka ${ }^{3}$ and Masahiko Inamori ${ }^{4 *}$ \\ ${ }^{1}$ Gastroenterology Division, Yokohama City University Hospital, Yokohama, Japan; ${ }^{2}$ Department of Medical Education, Yokohama City \\ University School of Medicine, Yokohama, Japan; ${ }^{3}$ Marketing Department, Kyowa Hakko Kirin Co., Ltd. Tokyo, Japan; and ${ }^{4}$ Office of \\ Postgraduate Medical Education, Yokohama City University Hospital, Yokohama, Japan
}

\begin{abstract}
Background/Aims
The gastrointestinal motility effects of endogenous incretin hormones enhanced by dipeptidyl peptidase-IV (DPP-IV) inhibitors have not yet been sufficiently investigated. The aim of this study was to determine whether single pre-prandial sitagliptin, the DPP-IV inhibitor, administration might have an effect on the rate of liquid gastric emptying using the ${ }^{13} \mathrm{C}$-acetic acid breath test.

\section{Methods}

Ten healthy male volunteers participated in this randomized, two-way crossover study. The subjects fasted for overnight and were randomly assigned to receive $50 \mathrm{mg}$ sitagliptin 2 hours before ingestion of the liquid test meal $(200 \mathrm{kcal}$ per $200 \mathrm{~mL}$, containing $100 \mathrm{mg}{ }^{13} \mathrm{C}$-acetate) or the test meal alone. Under both conditions, breath samples were collected for 150 minutes following the meal. Liquid gastric emptying was estimated by the values of the following parameters: the time required for $50 \%$ emptying of the labeled meal $\left(T_{1 / 2}\right)$, the analog to the scintigraphy lag time for $10 \%$ emptying of the labeled meal $\left(T_{\text {lag }}\right)$, the gastric emptying coefficient and the regression-estimated constants ( $\beta$ and $k$ ), calculated by using the ${ }^{13} \mathrm{CO}_{2}$ breath excretion curve using the conventional formulae. The parameters between the 2 test conditions were compared statistically.
\end{abstract}

\section{Results}

No significant differences in the calculated parameters, including $T_{1 / 2}, T_{\text {lag, }}$ gastric emptying coefficient or $\beta$ and $\kappa$, were observed between the 2 test conditions.

\section{Conclusions}

The present study revealed that single-dose sitagliptin intake had no significant influence on the rate of liquid gastric emptying in asymptomatic volunteers.

(J Neurogastroenterol Motil 2013;19:227-232)

Key Words

Breath tests; Gastric emptying; Sitagliptin

Received: November 6, 2012 Revised: February 21, 2013 Accepted: March 3, 2013

(c) This is an Open Access article distributed under the terms of the Creative Commons Attribution Non-Commercial License (http://creativecommons. org/licenses/by-nc/3.0) which permits unrestricted non-commercial use, distribution, and reproduction in any medium, provided the original work is properly cited.

*Correspondence: Masahiko Inamori, MD, PhD

Gastroenterology Division, Yokohama City University School of Medicine, 3-9 Fukuura, Kanazawa-ku, Yokohama 236-0004, Japan Financial support: None.

Tel: +81-45-787-2640, Fax: +81-45-784-3546, E-mail: inamorim@med.yokohama-cu.ac.jp

Conflicts of interest: None.

Author contributions: TN analyzed, collected the clinical data and wrote the manuscript, with contributions from MI. YS, HI, EY, HO, ES and TH were responsible for the design of the study and collected the clinical data. TN, KH, HE CN and MI performed the statistical analyses. TK, HT, KF, MY, AG, AK, NK, EG, SM, AN and MI analyzed the clinical data and participated in the design and coordination of the study. All authors read and approved the final manuscript. 


\section{Introduction}

The incretin hormones, glucagon-like peptide-1 (GLP-1) and glucose-dependent insulinotropic polypeptide (GIP), are peptides secreted from the intestine into the circulation in response to food ingestion, and they help manage glycemic control by regulating insulin and glucagon release, slowing gastric emptying, and reducing caloric intake. ${ }^{1-4}$ Physiologically, the clinical utility of native GLP-1 and GIP is limited because they are rapidly degraded and inactivated by the enzyme dipeptidyl peptidase-IV (DPP-IV). ${ }^{5,6}$

Inhibition of this enzyme leads to an increase in circulating endogenous GLP-1 and GIP levels. Therefore, DPP-IV inhibitors are a novel therapeutic strategy for type 2 diabetes. Since the release of sitagliptin in 2006, numerous studies have documented the advantages of DPP-IV inhibitors in the management of type 2 diabetes mellitus. ${ }^{7-10}$ However, the effect of DPP-IV inhibitor-induced enhancement of endogenous incretin hormones on gastrointestinal motility has not yet been sufficiently investigated. ${ }^{11,12}$ In the present study, the pharmacological effects of pre-prandial single-dose sitagliptin administration on the rate of liquid gastric emptying were examined in healthy volunteers using a ${ }^{13} \mathrm{C}$-acetic acid breath test.

\section{Materials and Methods}

\section{Subjects}

The subjects were 10 asymptomatic male volunteers (median age 34 years, range 27-50 years). The height and weight of the subjects were as follows: median height, $169 \mathrm{~cm}$; height range, $162-181 \mathrm{~cm}$; median weight, $64.5 \mathrm{~kg}$; and weight range, 60-92 $\mathrm{kg}$. None of the subjects were habitual drinkers. All were non-smokers and none had a history of gastrointestinal disease or abdominal surgery. None of the subjects was on any routine medication at the time of the study.

The study (Clinical trial registry number: UMIN 000006213) was conducted in accordance with the Declaration of Helsinki. Prior to study initiation, written informed consent was obtained from all participants. The study protocol using the ${ }^{13} \mathrm{C}$-acetic acid breath test was approved by the Ethics Committee of Yokohama City University School of Medicine.

\section{${ }^{13} \mathrm{C}$-acetic Acid Breath Test}

Ten subjects participated in this randomized, two-way crossover study (Fig. 1). After overnight fasting (at least 8 hours), the subjects received $50 \mathrm{mg}$ sitagliptin orally 2 hours before ingestion of the test meal (sitagliptin condition) or the test meal alone (control condition) in a random sequence. The 2 test conditions were separated by a washout period of at least 7 days.

The test meal was a $200 \mathrm{kcal}$ per $200 \mathrm{~mL}$ liquid meal (Racol with milk flavor, Otsuka Pharmaceutical, Co., Ltd., Tokyo, Japan) containing $100 \mathrm{mg}$ of ${ }^{13} \mathrm{C}$-acetic acid (Cambridge Isotope Laboratories, Inc., USA), and the subjects were requested to consume the meal within 5 minutes.

Gastric emptying was measured using the ${ }^{13} \mathrm{C}$-acetic acid breath test while the subjects were seated. Breath samples were collected in air bags at baseline (before test meal) and at 5, 10, 15, 20, $30,40,50,60,75,90,105,120,135$ and 150 minutes after completion of the test meal ingestion. The ${ }^{13} \mathrm{CO}_{2} /{ }^{12} \mathrm{CO}_{2}$ ratio in collected breath samples was determined as the difference above baseline using non-dispersive infrared spectrophotometry (POCone, Otsuka Electronics Co., Ltd., Osaka, Japan).

\section{Data Analysis}

In accordance with the method reported by Ghoos et al, ${ }^{13}$ the percentage of ${ }^{13} \mathrm{CO}_{2}$ recovery in expired breaths per hour (percent dose per hour) against time was fitted to the formula $y(t)$ $=\mathrm{at}^{\mathrm{b}} \mathrm{e}^{\mathrm{ct}}$ by non-linear regression analysis, where $\mathrm{y}$ is the percentage of ${ }^{13} \mathrm{C}$ excretion in breath per hour, $\mathrm{t}$ is time in hours, and a, $b$, and $c$ are constants. The time-course of cumulative ${ }^{13} \mathrm{CO}_{2}$ recovery in expired breaths can be fitted to another formula, $\mathrm{z}(\mathrm{t})=$

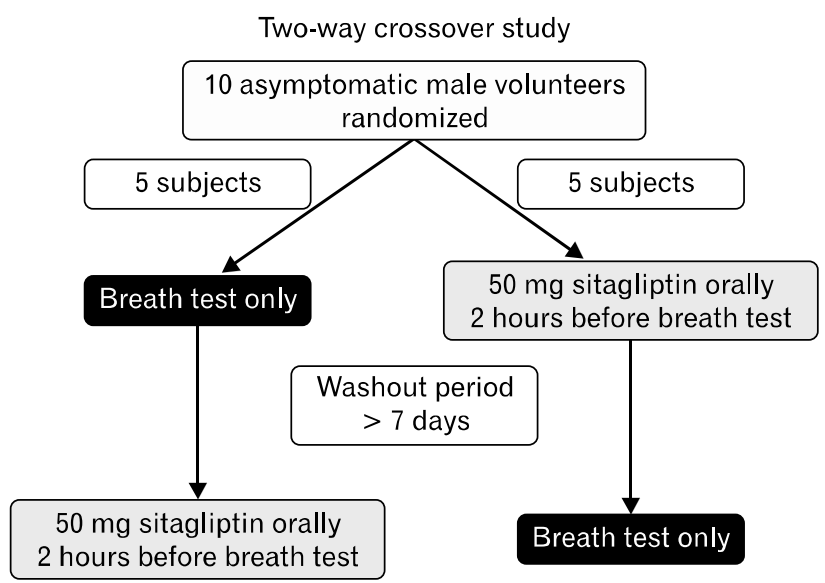

Figure 1. The flow of volunteers throughout the trial: two-way crossover study. 
$\mathrm{m}\left(1-\mathrm{e}^{-\mathrm{kt}}\right)^{\beta}$, where $\mathrm{z}$ is the percentage of the cumulative ${ }^{13} \mathrm{C}$ excretion in expired breaths and also an integral of $y(t), m$ is the cumulative ${ }^{13} \mathrm{CO}_{2}$ recovery at an infinite time, and $\beta$ and $\kappa$ are regression-estimated constants. Using the mathematical curve-fitting technique, $\beta$ and $\kappa$ were determined. A larger $\beta$ indicates slower emptying in the early phase, and a larger $\mathrm{K}$ indicates faster emptying in the later phase. The opposites are also true. The time required for $50 \%$ emptying of the labeled meal $\left(\mathrm{T}_{1 / 2}\right)$, the analog to the scintigraphy lag time for $10 \%$ emptying of the labeled meal $\left(\mathrm{T}_{\mathrm{lag}}\right)$ and the gastric emptying coefficient (GEC) were calculated as overall measures of gastric emptying: $\mathrm{T}_{1 / 2}=-\left[\ln \left(1-2^{-1 / \beta}\right)\right] / \kappa, \mathrm{T}_{\text {lag }}=$ $(\ln \beta) / \kappa$ and $\mathrm{GEC}=\ln (\mathrm{a}) .{ }^{13-15}$ These parameters were calculated using the Solver procedure in Excel 2010 (Microsoft Corp., Redmond, WA, USA).

\section{Statistical Methods}

Statistical evaluation was carried out using the Wilcoxon's signed-rank test. The level of significance was set at $P$-value $<$ 0.05 . We previously estimated that $90 \%$ of the subject delayed liquid gastric emptying in sitagliptin condition compare to control condition. The required sample size was therefore estimated to be 10 per group to have $80 \%$ power to detect differences at $P$ $<0.05$ level. All the statistical analyses were performed using Stat View software (SAS Institute, Cary, NC, USA).

\section{Results}

All 10 subjects completed this study, and no adverse events occurred during the study. No significant differences were observed in the $\mathrm{T}_{1 / 2}$ ([91.8: 72.2-98.4] vs. [94.2: 81.2-106.6]), $\mathrm{T}_{\mathrm{lag}}([52.8$ : 41.7-70.1] vs. [56.0: 44.8-65.5]), GEC ([4.19: 3.76-4.48] vs. [4.17: 3.30-4.52]), $\beta$ ([2.05: 1.71-3.23] vs. [2.09: 1.86-2.65]) and $\kappa([0.88: 0.76-1.04]$ vs. [0.86: 0.66-0.94]) (median: range, control vs. sitagliptin) between the control and experimental conditions (Fig. 2). These results indicated that sitagliptin had no significant effect on the rate of liquid gastric emptying.

\section{Discussion}

The present study was conducted to examine the changes in the rate of liquid gastric emptying after single pre-prandial administration of sitagliptin $50 \mathrm{mg}$ during the first 2.5 hours after ingestion of a liquid meal in healthy volunteers. There were no significant differences in any of the liquid gastric emptying parameters measured using the ${ }^{13} \mathrm{C}$-acetic acid breath test between the 2 test conditions, either ingestion of sitagliptin before the meal or the test meal alone. These results indicate that sitagliptin does not influence the rate of liquid gastric emptying.

After the introduction of DPP-IV inhibitors, numerous studies documenting their advantages in the management for type 2 diabetes mellitus patients have been published. ${ }^{8-10}$ However, to date, there have been a few studies reporting the pharmacological effects of DPP-IV inhibitors on the gastric emptying rate. In a previous study, DeFronzo et $\mathrm{al}^{12}$ reported that $100 \mathrm{mg}$ sitagliptin once a day for 2 weeks had no effect on the rate of gastric emptying in type 2 diabetes patients by an acetaminophen absorption method. Vella et $\mathrm{al}^{11}$ described that gastric emptying assessed by scintigraphy did not differ between type 2 diabetes patients treated with $50 \mathrm{mg}$ vildagliptin twice a day and placebo for 10 days. Our study was novel in that it examined the effect of single-dose pre-prandial sitagliptin $50 \mathrm{mg}$ on the rate of gastric emptying measured by a ${ }^{13} \mathrm{C}$-acetic acid breath test using a liquid meal in healthy volunteers.

One of the limitations in this study was the lack of information about actual serum GLP-1 concentrations enhanced by sitagliptin. Steady-state trough concentrations of sitagliptin have been reported to be achieved within 2 to 3 days of administration. ${ }^{14}$ On the other hand, it has also been reported that single administration of sitagliptin shows an equivalent pharmacokinetic profile compared with once-daily dosing in healthy subjects. ${ }^{14-16}$ Furthermore, single administration of sitagliptin $50 \mathrm{mg}$ produced by $80 \%$ or greater inhibition of DPP-IV activity at 2 hours after administration and over the following 12-hour period, and approximately 2-fold augmentation of postprandial active GLP-1 concentrations compared with placebo in healthy subjects was also observed. ${ }^{15}$ Herman et $\mathrm{al}^{17}$ reported that single administration of sitagliptin 25 and $200 \mathrm{mg}$ inhibited the enzymatic activity of DPP-IV by 80 to $96 \%$ at 2 hours after administration, respectively, and active GLP-1 levels increased greater than 2-fold after both doses in response to an oral glucose tolerance test (OGTT) at 2 hours after administration in patients with type 2 diabetes. They also showed that the near maximal glucose-lowering efficacy of single oral dose of sitagliptin was associated with $80 \%$ or greater plasma inhibition of DPP-4 activity. This level of DPP-IV inhibition corresponds to a plasma sitagliptin concentration of $100 \mathrm{nM}$ or greater and an augmentation of active GLP-1 and GIP levels of 2-fold or higher after an OGTT. ${ }^{17}$

Hence, active GLP-1 concentrations reached potent levels in this present study after single administration of sitagliptin 50 mg. However, these levels of serum GLP-1 concentration en- 
A

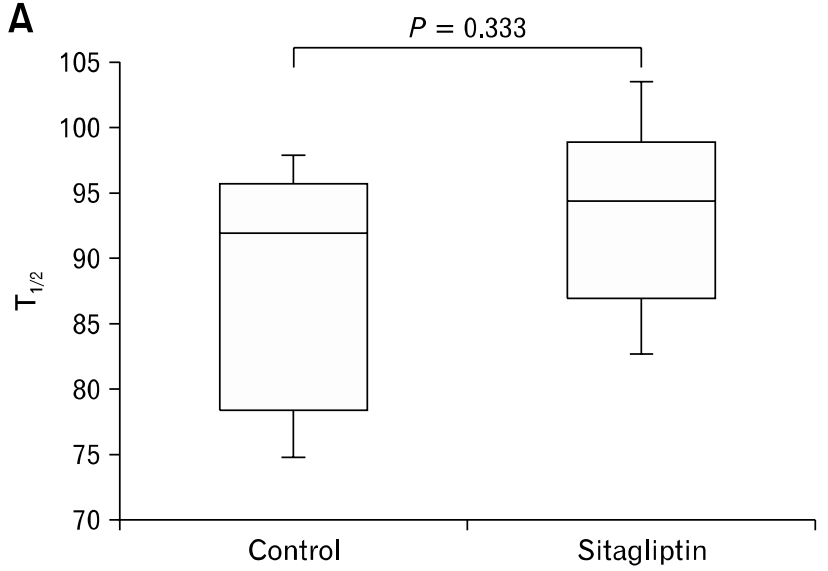

C

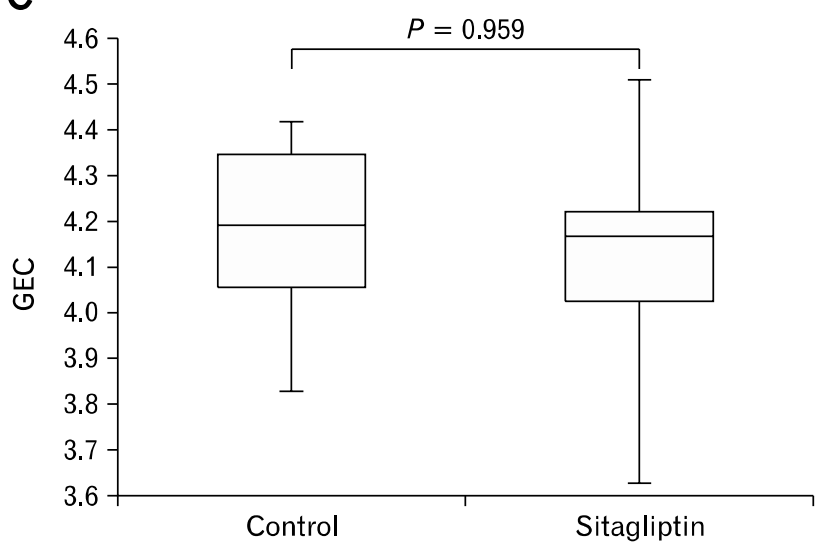

$E$

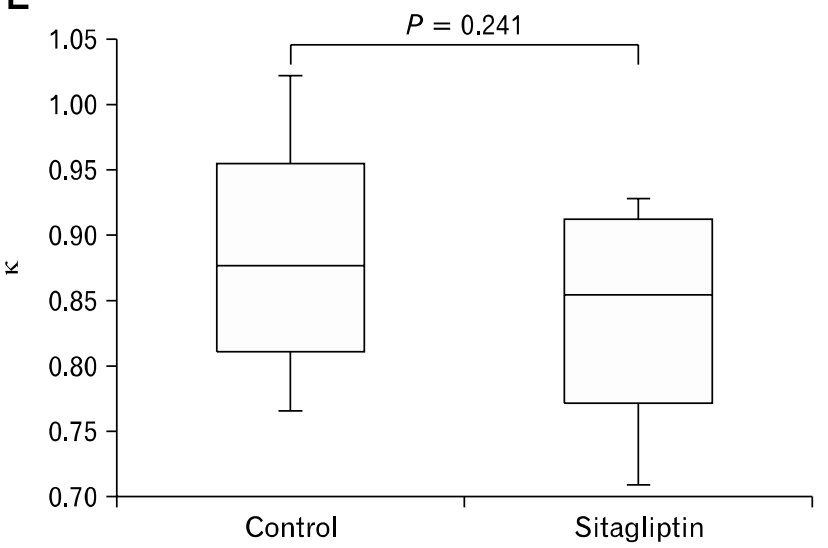

hanced by sitagliptin could be within the physiologic range. Thus, the explanation for the lack of effect on gastric emptying may be due to insufficient concentrations of active GLP-1 to delay gastric emptying, though active GLP-1 concentrations were sufficiently enhanced by sitagliptin to improve glycemic control.
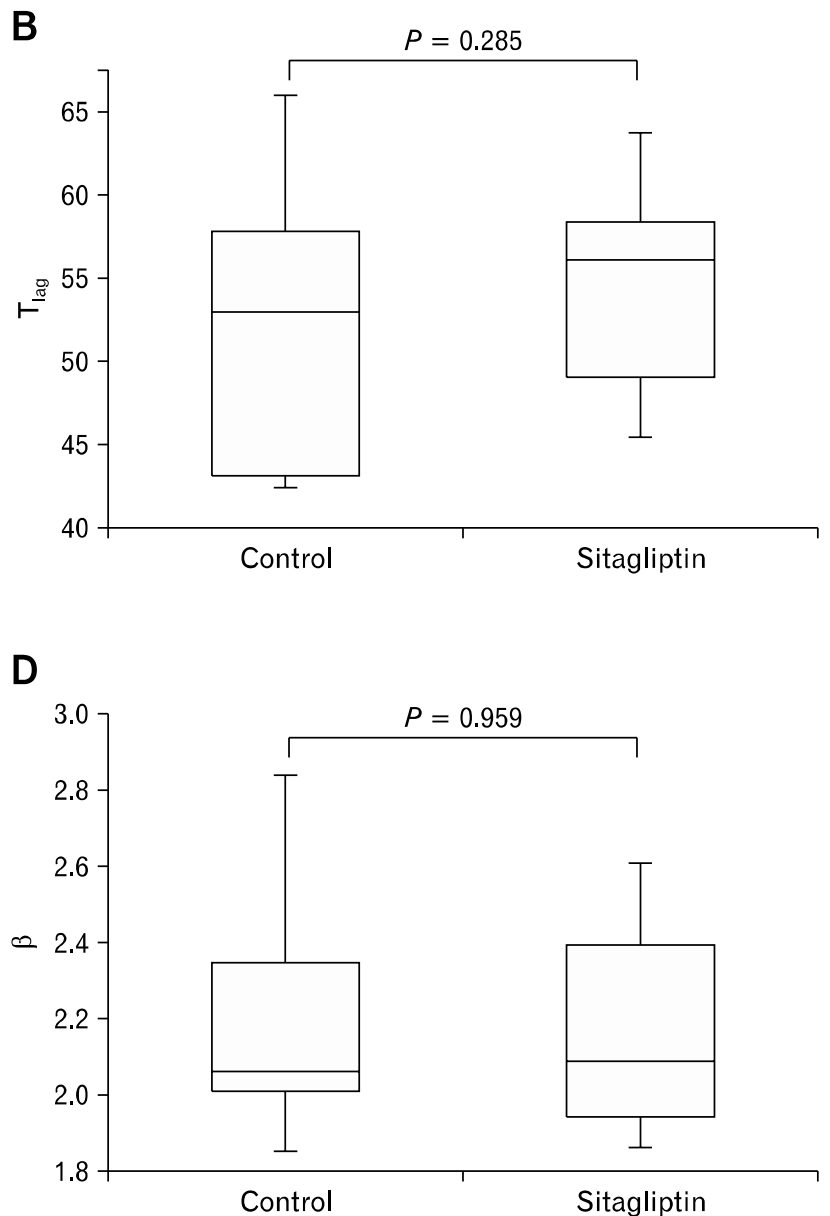

Figure 2. No significant differences were found in the $T_{1 / 2}(A), T_{\operatorname{lag}}(B)$, GEC (C), $\beta(\mathrm{D})$ or $\mathrm{k}(\mathrm{E})$ between the 2 study conditions, indicating that sitagliptin has no significant effect on the rate of gastric emptying. $T_{1 / 2}$, the time required for emptying $50 \%$ of the labeled meal (minutes); $\mathrm{T}_{\text {lag, }}$, the analog to the scintigraphy lag time for $10 \%$ emptying of the labeled meal (minutes); GEC, the gastric emptying coefficient; $\beta$ and $\kappa$, the regression-estimated constants.

This study was conducted in healthy, normoglycemic male subjects, which limited the extent to which the data can be extrapolated to patients with type 2 diabetes. As mentioned above, on the point of view of drug efficacy, the pharmacokinetic and pharmacodynamics profiles of sitagliptin are reported to be sim- 
ilar in healthy individuals and in those with type 2 diabetes. ${ }^{14-18}$ However, gastric emptying rates in the type 2 diabetes population have been reported to be delayed, unchanged, or accelerated. ${ }^{19-23}$ The investigation of gastric emptying rate in healthy subjects might be advantageous for understanding of the natural characteristics of pharmaceutical preparations in contrast to diabetic patients with high heterogeneity in their rates of gastric emptying.

It is also known that there are fundamental differences in the regulatory mechanisms underlying gastric emptying of solids and liquids. ${ }^{24,25}$ Additionally, the GLP-1 secretory patterns can be modulated by various ingested nutrients. ${ }^{26-28}$ Solid test meals, as mentioned in previous reports, ${ }^{11,12}$ may be more useful in clinical application.

Although scintigraphy is the current standard method for assessing gastric emptying, ${ }^{29,30}$ it is expensive, involves radiation exposure and requires the facilities of a department of nuclear medicine. The evaluation of gastric emptying using the ${ }^{13} \mathrm{C}$-acetic acid breath test has been developed as a non-radioactive alternative. The subject ingests ${ }^{13} \mathrm{C}$-labeled acetic acid, which passes through the stomach and is absorbed in the duodenum and superior small bowel. The ${ }^{13} \mathrm{C}$-labeled acetic acid is then metabolized in the liver and excreted from the lungs as ${ }^{13} \mathrm{CO}_{2}$. This pathway enables gastric emptying to be measured in a noninvasive manner. ${ }^{31-41}$ The accuracy of the breath test for measuring gastric emptying has been well supported by several validation studies demonstrating a strong correlation between the breath test and the scintigraphy. ${ }^{13,42-46}$

Ultimately, as demonstrated in previous studies, sitagliptin had no effect on the rate of liquid gastric emptying in asymptomatic volunteers.

\section{Acknowledgements}

The funding source had no involvement in the design, analysis, writing of the paper or decision to publish this work.

Special thanks to the medical staffs of the Gastroenterology Division, Yokohama City University Hospital, Kanagawa, Japan.

\section{References}

1. Elrick H, Stimmler L, Hlad CJ Jr, Arai Y. Plasma insulin response to oral and intravenous glucose administration. J Clin Endocrinol Metab 1964;24:1076-1082.

2. Drucker DJ, Nauck MA. The incretin system: glucagon-like peptide-1 receptor agonists and dipeptidyl peptidase-4 inhibitors in type 2 diabetes. Lancet 2006;368:1696-1705.
3. Drucker DJ. The biology of incretin hormones. Cell Metab 2006;3: 153-165.

4. Girard J. The incretins: from the concept to their use in the treatment of type 2 diabetes. Part A: incretins: concept and physiological functions. Diabetes Metab 2008;34(6 Pt 1):550-559.

5. Kreymann B, Williams G, Ghatei MA, Bloom SR. Glucagon-like peptide-1 7-36: a physiological incretin in man. Lancet 1987;2:13001304.

6. Mentlein R, Gallwitz B, Schmidt WE. Dipeptidyl-peptidase IV hydrolyses gastric inhibitory polypeptide, glucagon-like peptide-1(7-36)amide, peptide histidine methionine and is responsible for their degradation in human serum. Eur J Biochem 1993;214:829-835.

7. Kim D, Wang L, Beconi M, et al. (2R)-4-oxo-4-[3-(trifluoromethyl)-5,6-dihydro $[1,2,4]$ triazolo [4,3-a $]$ pyrazin-7 $(8 \mathrm{H})$-yl $]-1$ (2,4,5-trifluorophenyl)butan-2-amine: a potent, orally active dipeptidyl peptidase IV inhibitor for the treatment of type 2 diabetes. J Med Chem 2005;48:141-151.

8. Mest HJ, Mentlein R. Dipeptidyl peptidase inhibitors as new drugs for the treatment of type 2 diabetes. Diabetologia 2005;48:616-620.

9. Gerich J. DPP-4 inhibitors: what may be the clinical differentiators? Diabetes Res Clin Pract 2010;90:131-140.

10. Amori RE, Lau J, Pittas AG. Efficacy and safety of incretin therapy in type 2 diabetes: systematic review and meta-analysis. JAMA 2007; 298:194-206.

11. Vella A, Bock G, Giesler PD, et al. Effects of dipeptidyl peptidase-4 inhibition on gastrointestinal function, meal appearance, and glucose metabolism in type 2 diabetes. Diabetes 2007;56:1475-1480.

12. DeFronzo RA, Okerson T, Viswanathan P, Guan X, Holcombe JH, MacConell L. Effects of exenatide versus sitagliptin on postprandial glucose, insulin and glucagon secretion, gastric emptying, and caloric intake: a randomized, cross-over study. Curr Med Res Opin 2008; 24:2943-2952.

13. Ghoos YF, Maes BD, Geypens BJ, et al. Measurement of gastric emptying rate of solids by means of a carbon-labeled octanoic acid breath test. Gastroenterology 1993;104:1640-1647.

14. Bergman AJ, Stevens C, Zhou Y, et al. Pharmacokinetic and pharmacodynamic properties of multiple oral doses of sitagliptin, a dipeptidyl peptidase-IV inhibitor: a double-blind, randomized, placebo-controlled study in healthy male volunteers. Clin Ther 2006;28: 55-72.

15. Herman GA, Stevens C, Van Dyck K, et al. Pharmacokinetics and pharmacodynamics of sitagliptin, an inhibitor of dipeptidyl peptidase IV, in healthy subjects: results from two randomized, double-blind, placebo-controlled studies with single oral doses. Clin Pharmacol Ther 2005;78:675-688.

16. Herman GA, Mistry GC, Yi B, et al. Evaluation of pharmacokinetic parameters and dipeptidyl peptidase-4 inhibition following single doses of sitagliptin in healthy, young Japanese males. $\mathrm{Br} \mathrm{J}$ Clin Pharmacol 2011;71:429-436.

17. Herman GA, Bergman A, Stevens C, et al. Effect of single oral doses of sitagliptin, a dipeptidyl peptidase-4 inhibitor, on incretin and plasma glucose levels after an oral glucose tolerance test in patients with type 2 diabetes. J Clin Endocrinol Metab 2006;91:4612-4619.

18. Zerilli T, Pyon EY. Sitagliptin phosphate: a DPP-4 inhibitor for the treatment of type 2 diabetes mellitus. Clin Ther 2007;29:2614-2634.

19. Keshavarzian A, Iber FL, Vaeth J. Gastric emptying in patients with 
insulin-requiring diabetes mellitus. Am J Gastroenterol 1987;82:2935.

20. Phillips WT, Schwartz JG, McMahan CA. Rapid gastric emptying in patients with early non-insulin-dependent diabetes mellitus. $\mathrm{N}$ Engl J Med 1991;324:130-131.

21. Nowak TV, Johnson CP, Kalbfleisch JH, et al. Highly variable gastric emptying in patients with insulin dependent diabetes mellitus. Gut 1995;37:23-29.

22. Frank JW, Saslow SB, Camilleri M, Thomforde GM, Dinneen S, Rizza RA. Mechanism of accelerated gastric emptying of liquids and hyperglycemia in patients with type II diabetes mellitus. Gastroenterology 1995;109:755-765.

23. Kong MF, King P, Macdonald IA, et al. Euglycaemic hyperinsulinaemia does not affect gastric emptying in type I and type II diabetes mellitus. Diabetologia 1999;42:365-372.

24. Schulze K. Imaging and modelling of digestion in the stomach and the duodenum. Neurogastroenterol Motil 2006;18:172-183.

25. Kong F, Singh RP. Disintegration of solid foods in human stomach. J Food Sci 2008;73:R67-R80.

26. Morgan L, Elliott R, Tredger J, Nightingale J, Marks V. GLP-1 secretion in response to Nutrients in man. International Symposium on Glucagon-Like Peptide-1. Gopenhagen, Denmark, May 17-19, 1993 [abstract]. Digestion 1993;54:374-376.

27. D' Alessio D, Thirlby R, Laschansky E, Zebroski H, Ensinck J. Response of tGLP-1 to nutrients in humans. International Symposium on Glucagon-Like Peptide-1. Gopenhagen, Denmark, May 17-19, 1993 [abstract]. Digestion 1993;54:377-379.

28. Göke R, Richter G, Kolligs F, Fehmann HC, Arnold R, Göke B. How do individual meal constituents influence the release of GLP-1 in humans? International Symposium on Glucagon-Like Peptide-1. Gopenhagen, Denmark, May 17-19, 1993 [abstract]. Digestion 1993;54:380.

29. Collins PJ, Horowitz M, Cook DJ, Harding PE, Shearman DJ. Gastric emptying in normal subjects - a reproducible technique using a single scintillation camera and computer system. Gut 1983;24: 1117-1125.

30. Glerup H, Bluhme H, Villadsen GE, Rasmussen K, Ejskjaer N, Dahlerup JF. Gastric emptying: a comparison of three methods. Scand J Gastroenterol 2007;42:1182-1186.

31. Mossi S, Meyer-Wyss B, Beglinger C, et al. Gastric emptying of liquid meals measured noninvasively in humans with [13C]acetate breath test. Dig Dis Sci 1994;39(12 suppl):107S-109S.

32. Inamori $\mathrm{M}$, Iida $\mathrm{H}$, Endo $\mathrm{H}$, et al. Aperitif effects on gastric emptying: a crossover study using continuous real-time ${ }^{13} \mathrm{C}$ breath test (BreathID system). Dig Dis Sci 2009;54:816-818.

33. Inamori M, Akiyama T, Akimoto K, et al. Early effects of peppermint oil on gastric emptying: a crossover study using a continuous real-time ${ }^{13} \mathrm{C}$ breath test (BreathID system). J Gastroenterol 2007;42: 539-542.
34. Yamanaka H, Inamori M, Fujisawa N, et al. Two cases of pyloduodenal stenosis: the efficiency of gastric emptying evaluation using ${ }^{13} \mathrm{C}$ continuous breath test (BreathID System). Digestion 2006;20;74: 238 .

35. Sakamoto Y, Kato S, Sekino Y, et al. Effects of domperidone on gastric emptying: a crossover study using a continuous real-time ${ }^{13} \mathrm{C}$ breath test (BreathID system). Hepatogastroenterology 2011;58: 637-641.

36. Ikeda $\mathrm{T}$, Inamori $\mathrm{M}$, Fujisawa $\mathrm{N}$, et al. Effects of body positions on gastric emptying with enteral nutrition: a crossover study using a continuous real time ${ }^{13} \mathrm{C}$ breath test (BreathID system). Hepatogastroenterology 2008;55:1905-1907.

37. Akimoto $\mathrm{K}$, Inamori $\mathrm{M}$, Iida $\mathrm{H}$, et al. Does postprandial coffee intake enhance gastric emptying?: a crossover study using continuous real time ${ }^{13} \mathrm{C}$ breath test (BreathID system). Hepatogastroenterology 2009;56:918-920.

38. Nonaka T, Kessoku T, Ogawa $\mathrm{Y}$, et al. Does postprandial itopride intake affect gastric emptying? A crossover study using the continuous real time ${ }^{13} \mathrm{C}$ breath test (BreathID system). Hepatogastroenterology 2011;58:224-228.

39. Sakamoto $Y$, Kato S, Sekino Y, et al. Change of gastric emptying with chewing gum: evaluation using a continuous real-time ${ }^{13} \mathrm{C}$ breath test (BreathID system). J Neurogastroenterol Motil 2011;17:174-179.

40. Nonaka T, Kessoku T, Ogawa Y, et al. Effects of histamine H2 receptor antagonists and proton pump inhibitors on the rate of gastric emptying: a crossover study using a continuous real-time ${ }^{13} \mathrm{C}$ breath test (BreathID system). J Neurogastroenterol Motil 2011;17:287293.

41. Sakamoto Y, Sekino Y, Yamada E, et al. Effect of oral sumatriptan on gastric emptying: a crossover study using a continuous real-time ${ }^{13} \mathrm{C}$ breath test (BreathID system). World J Gastroenterol 2012;18: 3415-3419.

42. Parkman HP, Jones MP. Tests of gastric neuromuscular function. Gastroenterology 2009;136:1526-1543.

43. Braden B, Adams S, Duan LP, et al. The [13C]acetate breath test accurately reflects gastric emptying of liquids in both liquid and semisolid test meals. Gastroenterology 1995;108:1048-1055.

44. Bromer MQ, Kantor SB, Wagner DA, Knight LC, Maurer AH, Parkman HP. Simultaneous measurement of gastric emptying with a simple muffin meal using [13C]octanoate breath test and scintigraphy in normal subjects and patients with dyspeptic symptoms. Dig Dis Sci 2002;47:1657-1663.

45. Gatti C, di Abriola FF, Dall'Oglio L, Villa M, Franchini F, Amarri $\mathrm{S}$. Is the ${ }^{13} \mathrm{C}$-acetate breath test a valid procedure to analyse gastric emptying in children? J Pediatr Surg 2000;35:62-65.

46. González A, Mugueta C, Parra D, et al. Characterisation with stable isotopes of the presence of a lag phase in the gastric emptying of liquids. Eur J Nutr 2000;39:224-228. 